\title{
LIMITACIONES AL EJERCICIO DE LA PATRIA POTESTAD. DE ROMA AL DERECHO MODERNO
}

\author{
Olga Marlasca Martínez \\ Universidad de Deusto
}

\section{Introducción}

En fechas recientes (mediados del año 2000) tuvo lugar, por parte del Consejo de Ministros español, la firma del Protocolo Facultativo de la Convención sobre los Derechos del Niño relativo a la venta de niños, la prostitución infantil y la utilización de menores en la pornografía, por el que los países firmantes se comprometen a tipificar en sus legislaciones penales cada uno de estos delitos y a incluirlos en todo tratado de extradición suscrito o que suscriban en el futuro. ${ }^{1}$ En la actualidad, con cierta frecuencia, desgraciadamente, aparecen en los medios de comunicación noticias que describen escenas crueles y perversiones sórdidas que tiene relación con el abandono, venta de vídeos con abusos y asesinatos de niños, etc. En esta misma línea, un estudio realizado por la fundación ANAR se refiere al siguiente dato: un 23,8 por ciento de padres usa el castigo físico ${ }^{2}$.

La historia de la patria potestad es la crisis y ocaso de una institución inicialmente patriarcal y autoritaria y, por consiguiente, absoluta ${ }^{3}$.

1 Asimismo, en fechas relativamente recientes, se ha de destacar, en el orden civil, la LO 1/1996, de 15 de enero, de Protección Jurídica del Menor, la cual presenta un rígido cuadro normativo que obstaculiza el detestable tráfico de niños.

2 En la celebración del undécimo aniversario de la Convención sobre los Derechos del Niño, el presidente de Unicef España, Joaquín Ruiz-Giménez, reveló la existencia de más de 100.000 niños en España en situación de explotación laboral. La OIT, por su parte, constata que en los países en desarrollo trabajan unos 250 millones de niños entre 5 y 14 años.

3 Vid. Díez-Picazo y Antonio Gullón: «Sistema de Derecho Civil», vol. IV. Derecho de familia y Derecho de sucesiones, 2. ${ }^{\mathrm{a}}$ ed. (Madrid, 1982), 367. 
En sociedades anteriores a la nuestra, las facultades del paterfamilias eran muy amplias y se traducían en una serie de derechos a favor del mismo, como eran el derecho de dar muerte al filius, imponerle toda clase de castigos; venderlo, donarlo, pignorarlo, entre otros. Pero no es menos cierto que determinadas disposiciones legales van limitando las amplias facultades del pater ya desde la época romana.

En el presente trabajo, no es nuestro propósito realizar un estudio exhaustivo acerca de la patria potestas ${ }^{4}$ que ejerce el paterfamilias; sino que desde nuestro ángulo de visión pretendemos destacar que la historia de la citada institución constituye, en conjunto, un proceso de debilitación de la autoridad paterna, de manera que si en la concepción antigua de la patria potestad destacaba el aspecto de derecho, en la concepción moderna se acentúa el de deber ${ }^{5}$. Son complejas las causas de tan importante transformación. Algunos autores la explican por la evolución política de los pueblos: en los primitivos, en que la familia era la única sociedad y la autoridad del padre la única autoridad, su poder había de ser robusto; mientras que en las civilizaciones adelantadas, en que al lado de la familia y su autoridad existen el Estado y la suya, todo lo que gana la última tiene que perderlo la primera ${ }^{6}$. Otros autores señalan también, junto a la razón de carácter político mencionada, otras causas, morales y sociales, que han contribuido al cambio de la institución. Concretamente en relación con el Derecho romano, se recuerda la corrupción y el amplio desarrollo de las actividades militares y comerciales que rompieron la íntima unión de la antigua familia romana al determinar la necesidad de reconocer al filius una capacidad patrimonial; se indica también el influjo de las costumbres de Grecia y Egipto y se insiste, sobre todo, en la influencia del cristianismo con su concepción de la familia ${ }^{7}$.

Así pues, en las presentes líneas pretendemos retrotraernos a la antigüedad, concretamente a la época del Derecho romano, en primer lugar, y destacar las limitaciones legales en el orden personal que se impusieron al paterfamilias en el ejercicio de la patria potestad respecto de los hijos que de él dependían. Con posterioridad al citado derecho, dos textos legales de la época visigoda (el Código de Eurico y la Lex Visigothorum $^{8}$ ) aluden, asimismo, a los límites relativos a la autoridad

${ }^{4}$ Cf. la nota 11.

5 Cf. Castán VázQuez, J.M.a: La patria potestad (Madrid, 1960), 16.

6 VIOLLET: «Histoire du Droit civil français», 3. ${ }^{a}$ ed. (1905), 543, citado por CASTÁN VÁzQUEZ, J.M. ${ }^{\text {a: }}$ La patria potestad, 17.

7 RoBerTI: «Patria potestas e paterna pietas», en Studi Albertoni, I (1934), 259.

8 Lex Visigothorum, ed. K. Zeumer, en Monumenta Germaniae Historica (Leges), vol. I. Hannover-Leipzig (1902). En adelante, LV. 
paterna. Por otra parte, hay que tener además en cuenta que en la época bajomedieval muchas de las instituciones jurídicas de los textos legales romanos fueron objeto de recepción en textos legales posteriores en los términos a los que nos vamos a referir en los correspondientes epígrafes.

De esta manera, la disposición y división del trabajo se estructura en una serie de apartados: en primer lugar, se hace alusión a determinadas constituciones de emperadores de la época romana, contenidas en el Código Teodosiano9 ${ }^{9}$, así como en el Código de Justiniano, relativas a la prohibición de muerte, venta, donación y pignoración de los hijos; en el siguiente apartado se presentan las disposiciones del derecho visigodo que limitan, asimismo, las facultades del pater, pertenecientes, concretamente, al Código de Eurico y a la Lex Visigothorum, teniendo en cuenta la importancia que la citada Lex como cuerpo legal tuvo posteriormente en la Edad Media española. Al final de la disposición de la LV se incluye la versión de la misma contenida en el Fuero Juzgo ${ }^{10}$. A continuación se hace referencia a las disposiciones de los textos legales medievales que son objeto de la recepción del ius commune y que tienen relación con el tema objeto de nuestro estudio. Hacemos alusión, asimismo, a determinados aspectos acerca de la patria potestad regulados en la Ley de Matrimonio Civil de 1876. Por último, unas breves consideraciones relativas a la concepción de la patria potestad y los límites al ejercicio de la misma en el derecho actual.

${ }^{9}$ El Código Teodosiano es una compilación de constituciones imperiales que se promulgó con carácter oficial por los emperadores Teodosio II (Oriente) y Valentiniano III (Occidente) el año 433. El Código citado tuvo gran difusión: en Oriente estuvo en vigor hasta la época de Justiniano, cuyo Código (534) recogió muchas constituciones del Teodosiano. En Occidente, sobrevivió al Imperio ya que en gran parte quedó recogido en la Lex Romana Visigothorum (506) y a través de ella tuvo gran difusión en la Alta Edad Media occidental, $c f$. CHURRUCA, J., con la colaboración de MENTXAKA, R.: Introducción histórica al Derecho Romano, 7. ${ }^{a}$ ed. revisada (Bilbao, 1994), 222-223. Las constituciones del Código Teodosiano se citan por la ed. de Mommsen, vol. I (Berlín, 1954).

${ }^{10} \mathrm{La}$ compilación legislativa, promulgada por Recesvinto, se la conoce por los diferentes nombres de Lex Visigothorum, Liber Iudiciorum o Liber Iudicum, cf. datos más concretos sobre la citada Ley en la nota 65; debe destacarse, además, que la citada compilación se traduce al castellano en el siglo XIII con el nombre de Fuero Juzgo. En relación con el citado Fuero, se utiliza la edición de M. Martínez Alcubilla, en Códigos Antiguos de España. 


\section{El precedente romano}

\subsection{Consideraciones previas}

Como anteriormente se ha dejado constancia, no es nuestra intención tratar de forma exhaustiva la institución de la patria potestas romana, que ha sido estudiada por numerosos romanistas ${ }^{11}$, sino que pretendemos destacar en este apartado tan sólo unas breves consideraciones acerca de la misma. Como es sabido, se conoce con la expresión citada, la autoridad que el paterfamilias en el Derecho romano, ejerce sobre todas las personas que forman parte de la familia agnaticia. Además, el poder del paterfamilias sobre las personas a él sometidas era originariamente absoluto ${ }^{12}$, de manera que primitivamente no se diferenciaba del ejercicio sobre los esclavos, sobre la mujer que ha contraído matrimonio cum manu y sobre las personas alieni iuris que le han sido entregadas mediante la mancipatio correspondiente ${ }^{13}$. Ha de destacarse también que «el poder del pater, al contrario de lo que ocurría en los Derechos griegos y germánico, subsistía sobre el hijo de familia que hubiese alcanzado la mayor edad» ${ }^{14}$. El mismo Gayo ${ }^{15}$ afirma que la

11 La institución ha sido estudiada por numerosos romanistas, entre otros, podemos mencionar: BIONDI, B.: Il Diritto romano cristiano, III. La famiglia. Rapporti patrimoniali. Diritto publico (Milano, 1954), el autor dedica un capítulo: «La patria potesta, basi e fini della famiglia». Bonfante: Corso di Diritto romano. Diritto di famiglia (Roma, 1925), 69 ss. CASTEllo: Studdi sul diritto familiare e gentilizio romano (Milano, 1924), 69 ss. DE VISSCHER: «Il concetto di potestà nell'organizzacione dell'antico Diritto romano», en Conference romanistiche, 3 ss. KASER: «Der Inhalt der patria potestas», en ZSS, 58 (1938), 62 ss. WeSTRUP: Family, property and Patria potestas (London, 1936). RoBerTI: «Patria potestas» e «paterna pietas», en Studi Albertoni, I (1934). Más recientemente, la institución ha sido estudiada, entre otros, por OTERO, A.: «La patria potestad en el Derecho histórico español», en AHDE, 26 (1956), 209 ss. CASTÁN VÁZQUEZ: La patria potestad (Madrid, 1960).

12 Vid., entre otros, Iglesias, Juan: Derecho romano, 531 ss. ARias Ramos, J.: Derecho romano, II. Obligaciones, Derecho de familia. Derecho de sucesiones. Décima edición (Madrid, 1966), 722 ss. Giménez-Candela, T.: Derecho privado romano (Valencia, 1999), 228 ss. Asimismo, KASER: Derecho romano privado, 5. ${ }^{\mathrm{a}}$ ed. alemana. Trad. esp. por Santa Cruz Teijeiro (Reus, 1968), 275, se refiere a una hegemonía ilimitada del poderhabiente, la cual viene suavizada por el Derecho sacro y la costumbre y en la época de Augusto por limitaciones creadas por el mismo Derecho privado. La patria potestas, constituía, en frase de WINDSCHEID, «una potestad puramente egoísta», cuya extensión se determinaba sólo en interés del padre.

13 Cf. ARIas Ramos: Derecho Romano, II, 722.

14 KASER, Max: Derecho romano privado, 276.

15 Gayo, 1,55: Quod ius proprium civium Romanoram est; fere enim nulli alii sunt homines qui talem in filios suos habent potestatem, qualem nos habemus. 
patria potestas es una institución propia de los cives romani, sin comparación en pueblo alguno.

Asimismo, hay que tener en cuenta que la evolución de la patria potestas en el Derecho romano presenta como hitos inicial y final dos concepciones opuestas de la misma. La patria potestad comienza como un poder despótico concebido en provecho del que la ejerce, según establece Arias Ramos ${ }^{16}$, y termina considerándose como una autoridad tuitiva, destinada a beneficiar con su protección a los sometidos a ella. En definitiva, la patria potestas, en su estructura originaria, supone poder y no deber hacia los sometidos, a no ser en la esfera moral. El Derecho se detiene ante la patria potestas y no atraviesa el umbral de la familia ${ }^{17}$. En la nueva concepción de la institución influyeron una serie de razones, a las que nos hemos referido anteriormente, además del cristianismo, con su nueva concepción de la familia. Más adelante, la patrística, desarrollando las enseñanzas de San Pablo, presenta una nueva concepción de la familia y de la patria potestas ${ }^{18}$, de tal manera que esta nueva concepción influye en la legislación a partir de Constantino, en los términos a los que nos vamos a referir más adelante.

La patria potestas, en su concepción originaria, se concreta en una serie de facultades a favor del pater en relación con el filius, como son: el derecho de vida y muerte, ius vitae necisque, que constituye el más alto exponente del poder de coerción del padre ${ }^{19}$; comprende, además, el citado derecho, la posibilidad de imponerle toda clase de castigos. Tiene el pater, asimismo, el ius exponendi, esto es, el derecho de exponer al hijo de familia, y el ius vendendi, derecho de vender a los individuos que están integrados en la citada institución. Dentro de las facultades que componen la patria potestas, están, además, el derecho del pater de entregar en noxa al filiusfamilias para liberarse de esa forma de responsabilidad como consecuencia de los posibles daños que el mismo cometa frente a terceros pertenecientes a otra familia. Desde el punto de vista procesal, puede el pater reclamar al filius con la misma acción que le sirve para reclamar las cosas de las que es propietario: esto es, la reivindicatio.

16 ARIAs Ramos: Derecho romano, II, 722. No hacemos alusión al aspecto patrimonial de la patria potestas que tiene relación con la concesión por el pretor de las actiones adiecticiae qualitatis y la constitucion de los peculios a favor de los hijos.

17 Cf. Volterra: «Sui mores della famiglia romana», en Rend. Acc. Lincei (1949), 521 ss. Citado por OTERO: «La patria potestad en el derecho histórico español», en $A H D E$, 26 (1956), 212.

18 ROBERTI: «Patria potestas e paterna pietas», 264 ss.

19 KASER, Max: Derecho romano privado, 276. 
No obstante, es indudable que la presión del ambiente social y el afecto natural - lo más frecuente sería que el filiusfamilias tuviese un parentesco consanguíneo más o menos próximo con relación al jefe familiar- mitigaron en la práctica el rigor de un poder teóricamente tan absoluto $^{20}$. Existe, además, toda una evolución histórica por la cual, a través de graves restricciones en los poderes del pater e imposición de obligaciones, la patria potestas, según Kaser, se comienza a concebir como officium, es decir, como un deber de protección y de asistencia ${ }^{21}$. Asimismo, «la sucesiva intervención estatal —en los términos a los que nos vamos a referir en el siguiente apartado-, en consonancia con las nuevas concepciones sociales, acabó por destruir al viejo mundo de conceptos sobre el que descansaba la familia» ${ }^{22}$.

\subsection{Disposiciones legales que establecen limitaciones al ejercicio de la patria potestas}

2.2.1. En primer lugar, en el orden personal, por lo que respecta al derecho de vida y muerte (ius vitae necisque), hay que tener en cuenta, como anteriormente se ha dicho, que la moral influyó dulcificando el rigor de este poder y exigió al padre que las penas graves, sobre todo la de muerte, no fuesen impuestas por él arbitrariamente, sino como juez y después de oír el consejo de parientes (iudicium domesticum) ${ }^{23}$. El ejercicio abusivo del mismo fue prohibido ya por las XII Tablas ${ }^{24}$. También un texto de Ulpiano en Dig. 48,8,2 25, establece que el padre no puede matar a su hijo sin que haya sido oído, sino que debe acusarlo ante el prefecto o el gobernador de la provincia.

La legislación de la época del principado castigó severamente los abusos derivados de la potestas del paterfamilias; podemos referirnos a algunos textos recogidos en el Digesto de Justiniano. Concretamente, un texto de Papiniano en Dig. 37,12,5, alude a una disposición del emperador Trajano la cual obliga a emancipar al filius maltratado por el

20 Cf. ARIas Ramos: Derecho Romano, 723.

${ }^{21}$ KASER, Max: «Der Inhalt der patria potestas», en ZSS, 58. Romanistiche Abteilung (Weimar, 1938), 62 ss.

22 IgLeSIAS, Juan: Derecho romano (Barcelona, 1972), 533. Se han mencionado supra una serie de causas de toda índole que fueron modificando la institución dando paso a una nueva concepción de la familia, $c f$. RoBERTI: «Patria potestas e paterna pietas», 259.

23 Cf. Ciceón: de fini., 1,24; Val. Máx. 5,8,2.

24 KASER, Max: Derecho romano privado, 276.

25 Dig.48,8,2. El texto de Ulpiano en el libro I de Adulteriis, establece: Inauditum filium pater occidere non potest, sed accusare eum apud praefectum praesidemve provinciae debet. 
pater $^{26}$. Asimismo, un texto de Marciano en Dig. 48,9,5 ${ }^{27}$ nos informa de una disposición de Adriano que castiga con la deportartio in insulam al pater que mata al hijo latronis potius (more) quam patris iure. También el ius vitae et necis es testimoniado por Papiniano, en (Collatio Legum, 4,8,1 ${ }^{28}$ y condenado por la ética cristiana.

En una constitución de Constantino del año 323, dirigida al prefecto de la ciudad y contenida en CTh 4,8,6, se hace mención al ius vitae necisque como institución vigente en otro tiempo ${ }^{29}$. El mismo emperador castigaba con la pena del parricidio a los que mataron a sus padres, así como a sus hijos ${ }^{30}$. Así, la muerte de un hijo (y de otros parientes cercanos) constituye un delito de homicidio cualificado. De esta manera, hace reo de la pena propia del parricidio - la poena cullei ${ }^{31}$ a quien mata al hijo.

Finalmente, una constitución de Valentiniano en CTh 9,13,1 ${ }^{32}$ lleva a cabo la abolición del ius vitae necisque y declara competentes a los jueces y no a los padres para castigar a los hijos por faltas graves.

26 Dig. 37,12,5. Divus Traianus filium, quem pater mala contra pietatem afficiebat, coegit emancipare, quo postea defuncto pater, ut manumissor, bonorum possessionem sibi competere dicebat; sed consilio Neratii Prisci et Aristonis ei propter necessitatem solvendae pietatis denegata est.

27 Dig. 48,9,5 Marcianus libro 14 Institutionem.-Divus Hadrianus, fertur, quum in venatione filium suum quidam necaverat, qui novercam adulterabat, in insulam eum deportasse, quod latronis magis, quam patris iure eum interfecit; nam patria potestas in pietate debet, non atrocitate consistere.

28 Collatio 4,8. Papinianus, libro singulari de adulteris \{et titulo\}: 1. Cum patri lex regia dederit in filium uitae necisque potestatem, quod bonum fuit lege conprehendi, rescribere: nam scire cupio. Respondit: numquid ex contrario praestat nobis argumentum haec adiectio, ut non uideatur lex non habenti dedisse, sed occidi eam cum adultero iussisse, ut uideatur maiore aequitate ductus adulterum occidisse, cum nec filiae pepercerit? Cf., asimismo, Quintiliano: Declamationes, 6.14.

29 Asimismo, la constitución en CJ 8,47,10, en los siguientes términos: Imp. Constantinus A. ad Maximum, Praefectus urbi.- Libertati a maioribus tantum impensum est, ut patribus, quibus ius vitae in liberos necisque potestas olim erat permissa eripere libertatem non liceret.

${ }^{30}$ Se trata de una constitución del año 318 recogida en CTh 9,15,1 = CJ 9,17,1. El emperador Constantino al Vicario de Africa.- Si quis parentis aut filii aut omnino affectionis eius, quae nuncupatione parricidii continetur, fata properaverit, sive clam sive pala id fuerit enisus, poena parricidii punietur, neque gladio, neque ignibus, neque ulli alli solemni poenae subiugetur, sed insutus culeo cum cane et gallo gallinaceo et vipera et simia, et inter eas ferales angustias comprehensus serpentium contuberniis misceatur, et ut regionis qualitas tulerit, vel in vicinum mare vel in amnem proiiciatur, ut omni elementorum usu vivus carere incipiat, et ei coelum superstiti, terra mortuo auferatur.

${ }^{31}$ La citada pena consistía en encerrar a los parricidas en un saco de cuero para tirarlos al mar.

32 CTh 9,13,i [ = BREV. 9,10,11. Impp. Valentinianus et Valens AA. Ad Senatum. In corrigendis minoribua pro qualitate delicti senioribus propinquis tribuimus potestatem, ut, 
2.2.2. Por lo que respecta al ius exponendi ${ }^{33}$, otra de las facultades que integran la patria potestas, no es objeto de estas prohibiciones, pero se producen una serie de consecuencias, según consta en las constituciones de algunos emperadores a las que nos vamos a referir. Las XII Tablas ordenaban la exposición de las criaturas deformes. En el derecho postclásico, la exposición es tolerada: concretamente, tenemos que en el CTh 5,9, bajo la rúbrica: De expositis, se recogen algunas constituciones sobre la materia. En primer lugar, la constitución de Constantino, contenida en CTh 5,9, ${ }^{34}$, establece que quien asume la crianza de un hijo expuesto tendrá sobre él la patria potestad o el dominio, según que lo haya tratado como hijo o como esclavo, y por tanto cesa el poder paterno o dominical de quien lo hubiere expuesto. Asimismo, otra constitución de los emperadores Honorio y Teodosio en CTh 5,9,2 ${ }^{35}$, tiene relación con

quos ad vitae decora domesticae laudis exempla non provocant, saltem correctionis medicina conpellat. Neque nos in puniendis morum vitiis potestatem in inmensum extendi volumus, sed iure patrio auctoritas corrigat propinqui iuvenis erratum et privata anidmadversione conpescat. Quod si atrocitas facti ius domesticae emendationis excedit, placet enormis delicti reos dedi iudicum notioni.

En la interpretatio de la citada constitución se establece: Propinquis senioribus lege permittitur errorem vel culpas adulescentium propinquorum patria districtione corrigere, id est ut, si verbis vel verecundia emendari non possunt, privata districtione verberibus corrigantur. Quod si gravior culpa fuerit adulescentis, quae privatim emendari non possit, in notitiam iudicia deferatur.

33 Algunos autores se refieren en sus obras al ius exponendi, entre otros, $c f$. SUETONIO: Claudio, 27. El uso de la exposición de niños recién nacidos es común a los romanos, griegos, germanos e hindúes, $c f$. CASTÁN: La patria potestad, 22, nota 51.

${ }_{34}$ CTh 5,9,1. Imp. Constantinus A. Ad Ablavium Praefectam Praetorio. Quicumque puerum vel puellam, proiectam de domo patris vel domini voluntate scientiaque, collegerit ac suis alimentis ad robur provexerit, eundem retineat sub eodem statu, quem apud se collectum voluerit agitare, hoc est sive filium sive servum eum esse muluerit: omni reperitionis inquietudine penitus submovenda eorum, qui servos aut liberos scientes propria voluntate domo recens natos abiecerint.

En la interpretatio de la citada constitución de Constantino dirigida al Prefecto del Pretorio, en parecidos términos, se establece lo siguiente: Quicumque expositum recenti partu sciente patre vel matre vel domino collegerit ac suo labore educoverit, in illius, a quo collectus est, potestate consistat, seu ingenuum seu servum quem nutrivit esse voluerit.

${ }^{35}$ CTh 5,9,2 [ = BREV. 5,7,2]. Impp. Honorius et Theodosius AA. Melitio Praefecto Praetorio. Nullum dominis vel patronis repetendi aditum relinquimus, si expositos quadammodo ad mortem voluntas misericordiae amica collegerit, nec enim dicere suum poterit, quem pereuntem contempsit; si modo testis episcopalis subscriptio fuerit subsecuta, de qua nulla penitus ad securitatem possit esse cunctatio.

En la interpretatio de la Constitución perteneciente a los emperadores Honorio y Teodosio dirigida al Prefecto del Pretorio, contenida en CTh 5,9,2, se establece: Qui expositum puerum vel puellam sciente domino vel patrono misericordiae causa collegerit, in eius dominio permanebit: si tamen constestationi de collectione eius episcopus clericique subscripserint, quoniam postea suum dicere quisque non poterit, quem proiecisse probatur ad mortem. 
el ius exponendi, y se establece en la misma que quien haya recogido a un niño o niña expósitos, a sabiendas de su dueño o de su patrono, permanecerá en el dominio de quien lo recogió, después de que se haya probado que fueron expuestos para que murieran. En la época de Justiniano en una constitución del citado emperador, en CJ $1,4,24^{36}$, se concede al acogido la condición de ingenuo.

2.2.3. Por lo que respecta a las disposiciones relativas a la prohibición de la venta, donación y pignoración de los hijos por parte de los padres, se encuentran fundamentalmente en el Código Teodosiano, así como en el Código de Justiniano.

El ius vendendi que tuvo gran importancia en la antigüedad, decayó más rápidamente que el ius vitae necisque ${ }^{37}$. Hay que tener en cuenta que la patria potestad otorgaba al pater la facultad de vender al filius como si fuera un esclavo. Si la enajenación se realizaba trans Tiberim, se convertía en esclavo efectivo, y al volver a Roma no recobraba la ciudadanía ni la libertad $^{38}$. El caso era distinto cuando la venta tenía lugar en Roma; en este caso, se aplicaba el principio tradicional de que un ciudadano no podía ser esclavo en Roma, de esta manera el hijo vendido quedaba en una situación de mera privación de la libertad civil y no se convertía en esclavo ${ }^{39}$. Además, el poder del pater no se extinguía mientras el hijo permaneciera en tal estado de cuasiesclavitud; únicamente quedaba en suspenso y renacía tan pronto el adquirente lo

36 CJ 1,4,24. El emperador Justiniano a Demóstenes, Prefecto del Pretorio.- Nemini licere volumus, sive ab ingenuis genitoribus puer parvulus procreatus, sive a libertina progenie, sive servili conditione maculatus expositus sit, eum puerum in suum dominium vindicare, sive nomine dominii, sive adscriptitiae, sive colonariae conditionis. Sed neque his, qui eos nutriendos sustalerint, licentiam concedimus penitus cum quadam distinctione eos tollere. Sed nullo discrimine habito hi, qui ab huiusmodi hominibus educati, vel nutriti, vel aucti sunt, liberi et ingenui appareant, et sibi acquirant, et in posteritatem suam vel extraneos heredes omnia, quae haberunt, quo modo voluerint, transmittant...

37 Kunkel, W.: Derecho privado romano, 2. ${ }^{\mathrm{a}}$ ed. alemana. Trad. esp. por Prieto Castro (Barcelona, 1965), 411. Cf., asimismo, Bonfante: Corso di Diritto Romano, I. Diritto di famiglia (Roma, 1925), 80.

38 CiCERón: Pro Caec, 98.

39 Vid. KunKel, W.: Derecho privado romano, 411. Se refiere el citado autor a las causas que podían inducir al padre de familia a dar in mancipium a su hijo y que eran de muy diversas clases. De una parte, el ius vendendi ofrecía la posibilidad de emplear el trabajo de los hijos fuera del hogar doméstico antes de que el contrato consensual de servicios naciera. Entre las familias necesitadas, el in mancipio dare debió de ser, además, un medio de asegurar a los hijos el cuidado que el pater familias no podía prestarles satisfactoriamente. Asimismo, la entrega en mancipio era la forma de dar el hijo al tercero que hubiera sufrido un daño causado por él (noxae deditio). Idem, 412. 
emancipaba de su potestad. La enajenación del hijo de familia se efectuaba, como la de los esclavos, por vía de mancipación, y de aquí que esta situación de semiesclavitud fuera llamada in mancipio esse ${ }^{40}$.

En relación con el citado derecho a favor del paterfamilias, ya desde tiempos primitivos se establecen algunos límites procedentes de una norma, que la tradición atribuye a leyes reales antiquísimas ${ }^{41}$, y que con seguridad estaba contenida en las XII Tablas - tab. 4,242-, según la cual cuando un hijo de familia hubiera sido dado tres veces in mancipio, se extingue el poder paterno sobre el mismo, de manera que cuando el último adquirente le concede la libertad, la autoridad del pater no revive, sino que el filius queda liberado de la misma. A este respecto, establece $\mathrm{Kaser}^{43}$ que «es dudoso si el precepto fue una medida de carácter penal contra el padre, o más bien un negocio jurídico para liberar al hijo de la patria potestad».

El derecho de vender a los hijos resurge con la crisis económica del siglo III y los emperadores consienten esta práctica, motivada por la extrema pobreza de los ciudadanos. También es cierto que, como se desprende de las disposiciones que regulan esta materia, se aprecia en la regulación de la misma una línea legislativa algo sinuosa ${ }^{44}$, en los términos que vamos a ver en las siguientes líneas.

Nos referimos, en primer lugar, a una constitución del emperador Caracalla contenida en el libro 7 del Código de Justiniano, en el título De liberali causa. Así, concretamente es en CJ 7,16,145 donde se establece que la venta de hijos era res illicita et inhonesta. Asimismo, la prohibición de vender, donar o pignorar los propios hijos aparece ya en una ley de Diocleciano y Maximiano, entre los años 293-305, contenida en el CJ 4,43, ${ }^{46}$, en la que se dice que tal prohibición es manifesti iuris.

40 Cf. Gayo, 1,116 ss.

41 Dion De Hal, 227.

42 Tab. 4,2,b: Si pater filium ter venum duit filius [ = vendiderit] a patre liber esto. Gelio 1,132; Epit. Ulp. 10: Qui in potestate mancipiore sunt quemadmodum eo iure liberentur.

43 KASER: Derecho romano privado, 277.

${ }_{44}$ D’Ors: «El Código de Eurico», en Estudios visigóticos, II (Roma-Madrid, 1960), 222. Asimismo, KASER: Derecho romano privado, 277; se refiere a una legislación vacilante, influenciada por preceptos eclesiásticos prohibitivos de la venta de los hijos. Justiniano la permite solamente en el caso de gran indigencia de los padres.

45 Imp. Antoninus A. Saturnino.- Rem quidem illicitam et inhonestam admisisse te confiteris, quia proponis, filios ingenuos a te venumdatos Sed quia factum tuum filiis obesse non debet, adi competentem iudicem si vis, ut causa agatur secundum ordinem iuris.

${ }^{46}$ CJ 4,43,1: Imp. Diocletianus et Marimianus AA. Et CC. Papinianae.- Liberos a parentibus neque vendittionis, neque donationis titulo, neque pignoris iure, aut alio quolibet modo, nec sub praetextu ignorantiae accipientis, in alium transferri posse, manifesti iuris est. 
A propósito del ius vendendi en la época romana, según establece D'Ors ${ }^{47}$, «la historia de la legislación tardía relativa a la venta de hijos, en relación con la exposición, está determinada por una lucha moral que se produce en la conciencia del legislador cristiano entre la repulsión por la inmoralidad del acto y la precaución de no llevar las cosas al extremo de provocar la práctica de la exposición de infantes o del infanticidio». De esta manera, aun afirmando la libertad del hijo vendido, se admite la validez de la venta en favor de los que se hallan en extrema necesidad, como vemos en una constitución del año 329, contenida en CTh 5,10,1, perteneciente a Constantino, y se defiende el interés del comprador, limitándose el derecho de rescate de los padres a la condición de pagar ciertas compensaciones. Por otra parte, otro aspecto a destacar tiene relación con el contenido de una ley del año 391, recogida en el Código Teodosiano, concretamente en CTh 3,3,148. La citada ley, según D'Ors ${ }^{49}$, se ha creído inspirada por San Ambrosio, y en ella se dispone la recuperación del hijo sin compensación, con tal de que el hijo haya prestado servicio al comprador por un non minimi temporis spatium.

Pero todo esto no aparece de una manera uniforme y clara, sino con alternativas, reflejo de aquella lucha entre exigencia moral y prudencia ante la realidad, y entre castigo del padre y castigo del comprador. Con posterioridad, en el año 451, la novela 33 del emperador Valentiniano lleva la rúbrica: De parentibus qui filios distraxerunt et ne ingenui barbaris venundentur neque ad transmarina ducantur $^{50}$. La citada ley tiene lugar tras los efectos de un momento de hambre terrible que padeció el Imperio, de manera que en este contexto preocupa ante todo el salvar la vida del hijo y, posteriormente, si se quiere recuperar se impone para su rescate la devolución del precio más una cantidad proporcional del mismo en concepto de indemnización.

47 D’Ors, A.: «El Código de Eurico», 222.

48 En el Código Teodosiano, en el libro 3, bajo la rúbrica: De patribus, qui filios distraxerunt, se establece en CTh 3,3,1 [ = BREV. 3,3,1], lo siguiente: Omnes, quos parentum miseranda fortuna in servitium, dum victum requirit, addixit, ingenuitati pristinae reformentur. Nec sane remunerationem pretii debet exposcere, cui non minimi temporis spatio servitium satisfecit ingenui.

Asimismo, en la Interpretatio a la citada ley, se establece: Si quemcumque ingenuum pater faciente egestate vendiderit, non poterit in perpetua servitute durare, sed ad ingenuitatem suam, si servitio suo satisfecerit, non reddito etiam pretio revertatur.

49 D’Ors: «El Código», 222.

50 Nov. 33: Imp. Valentinianus a Aetio Patricio. 
Justiniano ${ }^{51}$, apremiado quizá por una práctica irreprimible en Oriente $^{52}$, establece que el derecho de venta podría aplicarse sólo a los recién nacidos y exige para la validez de la misma el requisito de la extrema necesidad de los padres y la facultad de poder recuperar la libertad del vendido mediante el pago de un rescate.

\section{Derecho visigodo ${ }^{53}$}

\subsection{Código de Euricos ${ }^{54}$}

Una vez analizada la regulación jurídica romana relativa a determinadas facultades que conforman la patria potestas y los límites legales

51 CJ 4,43,2, modificando la Ley de Constantino en CTh 5,10,1, establece lo siguiente: Si quis propter nimiam paupertatem agestatemque victus causa filium filiamve sanguinolentos vendiderit, venditione in hoc tantummodo casu valente emptor obtinendi eius servitii habeat facultatem. Liceal autem ipsi qui vendidit vel qui alienatus est, aut cuilibet alii ad ingenuitatem eum propriam repetere, modo si aut pretium offerat quod potest valere, aut mancipium pro huiusmodi praestet.

52 Cf. D’Ors: «El Código de Eurico», 222.

${ }^{53}$ El reino visigodo antes de su establecimiento definitivo en Occidente, se constituyó en estrecha relación con el Imperio, al que desde antiguo venía prestando servicios militares de frontera bajo la fórmula del foedus ( $c f$. GIBERT, Rafael: «El reino visigodo y el particularismo español», en Cuadernos del Instituto Jurídico Español, 5. Estudios visigóticos, I (Roma-Madrid, 1956), 17 y las notas 6 y 7). El primer período del asentamiento de los visigodos en las Galias y en la parte noroeste de la Península, dominio que por el Occidente llegó al parecer hasta Zaragoza, se inscribe en la estructuracion del Imperio Romano, en la etapa anterior a la caída de Roma por los hérulos ( $c f$., entre otros, ORLANDIs, J.: Historia de España. La España visigótica (Madrid, 1977), 59 ss. García Gallo, A.: «Consideración crítica de los estudios sobre la legislación y la costumbre visigoda», en AHDE (1974), 424 ss.). A partir del año 476, con la entrada de Odoacro en Roma, la situación sufrió transformaciones profundas que se manifestaron de forma desigual en los distintos territorios sobre los que estaban asentados los visigodos. Durante esta época perdura la misma estructura territorial y política y al mismo tiempo los órganos de la Administración romana continúan desarrollando las funciones de gobierno, con cierta intervención de los monarcas visigodos. Con Eurico, el primer monarca visigodo, y su hijo Alarico se da un paso más al ocupar éstos el lugar que antes había desempeñado el emperador, ejerciendo sus poderes y facultades. A partir de este momento es cuando podemos hablar propiamente de una legislación visigoda; entre otros, puede verse: ARANGIO RuIZ: Historia del Derecho romano, 4. ${ }^{a}$ ed.; trad. esp. (Madrid, 1989), 448 ss.; García Moreno, L.A.: Historia de la España visigoda (Madrid, 1989), 317 ss.; Lalinde Abadia: El Derecho en la Historia de la Humanidad (Barcelona, 1982), 38 ss. Finalmente, hemos de decir que son los visigodos uno de los pueblos germánicos más romanizados de los que se asientan en el antiguo territorio del Imperio Romano occidental. Entre los autores modernos no deja de reconocerse la profunda romanización de los reyes visigodos; sobre el particular, ver, entre otros, D'ORs: «El Código de Eurico», 9.

${ }^{54} \mathrm{El}$ Código de Eurico nos ha llegado de forma fragmentaria. En parte, a través del Palimpsesto Parisino (Lat. 12161) y, además, a través de ciertas leyes que pasaron como 
a las mismas que en muchas ocasiones se establecieron, nos centramos seguidamente en las disposiciones del derecho visigodo, contenidas fundamentalmente en el Código de Eurico y en la Lex Visigothorum y que tienen relación con el tema de nuestro estudio.

En primer lugar, conviene destacar que el Código de Eurico, aunque posee vestigios o detalles de costumbres germánicas, está profundamente romanizado; en su redacción intervinieron buenos conocedores del Derecho romano - como León de Narbona-, pertenece a la cultura jurídica romana existente en el sur de las Galias en la segunda mitad del siglo v y es, en suma, un monumento de Derecho romano vulgar ${ }^{55}$. Con anterioridad, Schwerin ${ }^{56}$ había establecido que la planificación del Código de Eurico delataba gran afinidad con las obras romanas, y encuentra una serie de paralelismos en la comparación que hace del Código de Eurico con las Sentencias de Paulo. Pero esta profunda romanización del texto no ha de verse como una «cristalización» del Derecho Romano oficial, es decir, de las leges e iura, sino más bien, como han puesto de relieve algunos autores, García Gallo ${ }^{57}$ e Iglesia Ferreirós ${ }^{58}$, entre otros, pretenden fijar por escrito un sistema jurídico más acorde con la realidad. Conviene recordar, asimismo, que muchas de las disposiciones del texto legal euriciano pa-

antiquae del Código de Leovigildo a la Lex Visigothorum. Cabe destacar, asimismo, como fuente de conocimiento indirecto, otros textos legales como la Lex Baiuvariorum y, en menor medida, la Lex Burgundionum y la Lex Salica. La doctrina, mayoritariamente, ha venido atribuyendo el Código a Eurico. El citado texto legal fue publicado según ZEuMER, Historia de la legislación, 67, después del año 469, pero antes del 481, alrededor del año 475. En adelante, CE. Un estudio de conjunto acerca del CE puede verse en D'ORS, A.: «El Código de Eurico», Estudios Visigóticos, II (Roma-Madrid, 1960). Establece el citado autor la fecha del CE en el año 476 d.C. y considera que el Código de Eurico es propiamente un edicto y no un codex como pudo ser el Código Teodosiano, $c f$. D'Ors, A.: «El Código de Eurico», 3 ss. Se utiliza fundamentalmente el CE en la edición de Alvaro D'Ors.

55 Vid. D’Ors, A.: «El Código de Eurico», 1-12. La romanización del Código se manifiesta en una serie de capítulos, $c f$. D'Ors, A.: «La territorialidad del Derecho de los visigodos», en Estudios visigóticos, I (Roma-Madrid, 1956), 114-116.

56 SCHWERIN: «Notas sobre la historia del Derecho español más antiguo», en AHDE, 1 (1924), 39.

57 García Gallo, A.: «Consideración crítica de los estudios sobre la legislación y la costumbre visigodas», en $A H D E, 44$ (1974), 437-442. Además, el citado autor establece, en relación con el texto legal euriciano, reproducido parcialmente en el palimpsesto de $\mathrm{Pa}-$ ris, que «dónde, cuándo y por obra de quién se ha promulgado el Código fragmentariamente recogido en el palimpsesto, no lo sabemos; todo lo que ha dicho son conjeturas, a veces totalmente aventuradas», Idem, 437.

58 IgLESIA FERREIRós: La creación del Derecho. Una historia de la formación de un derecho estatal español (Barcelona, 1992), 204. 
saron posteriormente a la ley de los visigodos con el nombre de antiquae 59 .

Por lo que se refiere a nuestro tema de estudio, quizá hubiese en el Código de Eurico un título con la rúbrica: de expositis ${ }^{60}$ simplemente, como hemos visto supra en CTh 5,9. Concretamente, en el cap. $299^{61}$ del citado texto legal se refiere a la ilicitud que supone el vender, donar o pignorar a los hijos por parte de los padres y las consecuencias que derivan de no tener en cuenta tal prohibición supone la pérdida del precio más las impensas pagadas por el comprador de un hijo que fue vendido por su padre.

El reunir en una misma disposición prohibitiva, como se acaba de ver: la venta, donación y pignoración, sólo era posible, según D’Ors, siendo ésta radical ${ }^{62}$. Hay que destacar, asimismo, que la prohibición que hemos visto en el texto de Eurico no parece inspirarse en la legislación cristiana, sino en la Constitución anteriormente citada de Diocleciano $^{63}$. Y sigue diciendo el citado autor que «la legislación conscientemente cristiana no podía ser tan radical, por la previsión de peores consecuencias, pues la venta de hijos es un mal menor frente a la exposición, y ésta un mal menor frente al infanticidio o al aborto» ${ }^{64}$.

59 En relación con las disposiciones antiquae pertenecientes a la Lex Visigothorum, véase la nota 65 .

60 Cf. D’Ors, A.: «El Código de Eurico», 151.

${ }^{61}$ Cap. 299: Parentibus filios suos vendere aut donare \{non liceat\} nec obpignerare; nec aliquid suo iure vendicabit qui acceperit sed magis praetium quod dedit perdat qui a parentibus filium comparavit.

$62 C f$. D'Ors, A.: «El Código de Eurico», 223.

${ }^{63} C f$. la constitución contenida en CJ 4,43,1, citada en la nota 46. Por lo que respecta a la prohibición de pignorar pudo servir de modelo al texto de Eurico, la disposición de PS 5,1,1 y Eth 95, aunque la pena de deportación que allí se señala (según D’ORS, A.: «El Código de Eurico», 223, nota 741), no podía ser mantenida por Eurico.

${ }^{64}$ D'Ors, A., 223. Establece además el citado autor que «en Occidente no existía una práctica de vender los hijos tan extendida como en Oriente, y de ahí que Eurico pudiera establecer una prohibición tan radical sin producir peores consecuencias en gran escala», ibidem, 223. 


\subsection{Lex Visigothorum ${ }^{65}$}

\subsubsection{Consideraciones previas ${ }^{66}$}

Nos referimos a continuación a la regulación de los límites impuestos al ejercicio de la patria potestad del pater contenida en la Lex Visigothorum $^{67}$. Contiene la citada Lex una elevada dosis de Derecho romano más o menos mezclado con otras adherencias de la época visi-

${ }^{65}$ La Lex Visigothorum, conocida también con los nombres de Liber Iudicum o Liber Iudiciorum, es un libro destinado a la práctica forense y consiste en una recopilación de las leyes promulgadas por los monarcas visigodos que lleva a cabo Recesvinto en el año 654. Tiene la citada obra desde sus orígenes una tradición compleja, ya que su constitución se hizo en distintas etapas y por obra de distintos personajes. Las leyes del Liber en la forma recesvindiana que ha llegado hasta nosotros - aunque no todas, pues hay alguna excepción-, van precedidas de una de las siguientes inscripciones: Antiqua, Flavius Recaredus Rex, Flavius Sisebutus Rex, Flavius Chindasvintus Rex, Flavius Gloriosus Reccesvindus Rex. De forma que, por un lado, recoge leyes cuyos autores aparecen mencionados, y de otro, leyes que estaban recogidas ya en libros. Las leyes que proceden de recopilaciones llevan la rúbrica: antiqua; si los redactores las corrigieron, las colocaron bajo la rúbrica antiqua enmendata. Un resumen de la historia de la legislación visigótica de Eurico a Witiza puede verse en ZEUMER: Historia de la legislación visigoda, trad. esp. por Carlos Clavería (Barcelona, 1944), 64 ss.; UREÑa y SMENJAUd: La legislación gótico-hispana (Leges Antiquiores-Liber Iudiciorum). Estudio crítico (Madrid, 1905), 45 ss. Un documentado escrito acerca de la LV en fechas recientes puede verse en GARCía LóPEZ, Y.: «Estudios críticos de la Lex Visigothorum», en Memorias del Seminario de Historia Antigua, V (Universidad de Alcalá de Henares, 1996). En el prólogo de la citada obra, establece la autora que trata de abordar el código de leyes visigodas desde dos ángulos que conforman dos partes bien distintas: 1) la historia material de los libros donde esas leyes se copiaron y circularon durante muchos siglos, y 2) el análisis interno de uno de los corpus de autoría segura - la del rey Egica - que contiene esa recopilación legal. Estas dos formas de acercarse a una legislación tienen relación, según nos dice la autora, con su condición de filóloga, y se apartan de los enfoques empleados más a menudo y más exhaustivamente en el código de leyes visigodas por historiadores de la Antigüedad tardía o la Alta Edad Media, e historiadores del Derecho. También, IgLESIA FERREIRós: La creación del Derecho. Una historia de la formación de un derecho estatal español (Barcelona, 1992), 203-237; puede verse en el citado autor un estudio del proceso de formación de la legislación visigoda.

${ }^{66}$ Hay que destacar el trabajo en relación con la patria potestad del profesor MEREA, P.: «O poder paternal na legislaçao visigotica», en Estudos de direito visigótico (Coimbra, 1948), 1-22; el citado autor, gran conocedor del derecho visigótico, se ocupó asimismo de estudiar la patria potestad en el Derecho de los territorios occidentales de la Reconquista de la época posterior a la invasión musulmana y anterior a la Recepción del Derecho romano en las Partidas. Idem, «Notas sobre o poder paternal no direito hispánico occidental», en Estudos de direito hispánico medieval, I (Coimbra, 1952), 83-112.

67 Son los visigodos uno de los pueblos germánicos más romanizados de los que se asientan en el antiguo territorio del Imperio Romano occidental. Entre los autores modernos no deja de reconocerse la profunda romanización de los reyes visigodos, vid., entre otros, D’Ors, A.: «El Código de Eurico», 9. 
goda $^{68}$ y se estructura la misma en 12 libros al igual que el Código de Justiniano, aunque Ureña ${ }^{69}$, siguiendo a Savigny, tras aludir a la división en doce libros, establece: «He aquí el único lazo de unión que entre ambos existe; en todo lo demás no hay correspondencia alguna, ni en las rúbricas ni en la distribución de la materia.»70

Por lo que respecta a las características relativas a la patria potestad en la época que nos ocupa, establece Merea que la legislación visigoda en materia de patria potestas continúa la tradición legislativa del Bajo Imperio, acentuando ciertos rasgos del Derecho romano postclásico ${ }^{71}$. Asimismo, establece King ${ }^{72}$, entre otras cosas, que «la autoridad paterna en el reino del siglo séptimo era pura sombra de lo que había sido en la época clásica», y «la palabra clave ahora era la pietas más que la potestas». Así, en algunas disposiciones de la ley se habla de naturalis

68 García y García, A., «El derecho común en Castilla durante el siglo XIII», en Glossae. Revista de Historia del Derecho Europeo, 5-6 (1993-94), 55 ss. Asimismo, establece el citado autor que se da en la Península un derecho romano soterrado o latente, aunque en una dosis muy diversa según que se tratara de las zonas peninsulares donde estaba en vigor o no el Liber Iudiciorum, ibidem, 55.

69 UREÑA y SMENJAUd: La legislación gótico-hispana, 447-448.

70 Admitido el alto grado de romanización de la LV, la doctrina se cuestiona el posible uso de las fuentes justinianeas en la citada lex. La doctrina del siglo XIX negó el posible uso de las mismas, entre otros, SAvigny, F.C.: en Storia del Diritto romano nel medioevo (Turín, 1854), reedición (Roma, 1972), 326 ss. Asimismo, cf. las conclusiones negativas de Churruca, Juan de: Las instituciones de Gayo en San Isidoro de Sevilla (Bilbao, 1975), 135-138 (resumen). Otros autores: LARRAOnA, A. y TABERA, A.: «El derecho justinianeo en España», Atti del Congresso Internazionale di Diritto Romano, II (Pavía, 1935), 103, establecen, entre otras cosas, que «en el estado actual de nuestros estudios pueden citarse algunos capítulos con reminiscencias textuales de fuentes justinianeas y más de una treintena inspiradas, en cuanto podemos juzgar, en el Digesto, en el Código, en las Novelas, en el Paulo íntegro». En la actualidad, IgLeSIA FerReirós, A.: La creación del Derecho. Una historia de la formación de un Derecho estatal español, vol. I (Barcelona, 1992), 234- 235, aunque mantiene sus dudas, se inclina a pensar en una posible influencia de las fuentes justinianeas en la ley de los visigodos. Así, cuando establece: «y sin embargo, es difícil renunciar a la idea de que el Derecho justinianeo haya podido tener alguna influencia. No hay pruebas, pero Recesvinto habla de las leyes de un pueblo extranjero, de instituciones extranjeras, y las mismas sirven para la enseñanza. Todo hace creer que Recesvinto está pensando en la obra de Justiniano».

$71 C f$. Merea, P.: «O poder paternal na legislaçao visigótica», en Estudos de Direito visigótico (Coimbra, 1948), 22. Hay que tener en cuenta que la legislación visigoda se inserta normalmente en la evolución del Derecho romano, cosa muy natural, dice D'ORs, A., «La territorialidad del Derecho de los visigodos», en Estudios visigóticos, I (Roma-Madrid, 1956), 105 ss., si se recuerda que los visigodos han recibido el Derecho privado romano y no han conservado uno propio de tipo germánico.

72 KING, P.D.: Derecho y sociedad en el reino visigodo. Versión esp. de M. Rodríguez Alonso (Madrid, 1981), 250. 
$\operatorname{pietas}^{73}$. Además, la patria potestad de la legislación visigoda, en consonancia con la regulación en el Derecho romano postclásico, se concibe como un officium en interés de los hijos y «esta concepción de la patria potestad visigoda se ve confirmada por la actitud de la legislación frente a las manifestaciones del poder absoluto del padre» ${ }^{74}$.

\subsubsection{Límites legales al ejercicio de la patria potestad en la Lex Visigothorum}

En primer lugar, por lo que respecta al ius vitae necisque, se combate el citado Derecho sancionándose la muerte del hijo en una disposición contenida en LV 6,5,18 ${ }^{75}$. Asimismo, el infanticidio se castiga con la pena capital en otra disposición, en este caso, en la LV 6,3,7, bajo la rúbrica: De his, qui filius suos aut natos aut in utero necant. Además, el juez de la tierra puede sustituir la pena de muerte del culpable por otro tipo de sanción, en estos términos, según la citada disposición: «...mox provincie iudex aut territorii talem factum reppererit, non solum operatricem criminis huius publica morte condemnet, aut si vite reservare voluerit, omnem visionem oculorum eius non moretur extinguere» ${ }^{76}$.

Por lo que respecta al derecho de exposición se encuentra regulado en la ley, en el tít. 4 del libro 4: De expositis infantibus, el cual consta

${ }^{73} C f$., entre otras, la LV 6,3,7.

74 Otero, A.: «La patria potestad en el Derecho histórico español», en AHDE, 26 (1956), 217. Se ha de destacar, asimismo, que MerEA, P.: «O poder paternal na legislaçao visigótica», en Estudos de Direito visigótico (Coimbra, 1948), 11 ss., examina varios textos que parecen favorables a la idea de un poder ejercido simultáneamente por los dos padres o de un poder ejercido por la madre a falta de padre.

${ }^{75}$ La edicion recesvindiana de la LV 6,5,18, establece lo siguiente: De his, qui proximos sanguinis sui occiderint.- Si patrem filius aut pater filium seu maritus uxorem aut uxor maritum aut mater filiam aut filia matrem aut frater ftatrrm aut soror sororem vel socerum gener aut socer generum vel nurus socrum aut socrus nurum vel quemcumque consanguinitate sibi proximum aut suo generi copulatum occiderit, morte damnetur. Quod si propter hoc homicida ad ecclesiam vel ad altaria sacra... Ervigio introduce la siguiente modificación: ... vel altaria sacra concurrerit, in potestate parentum vel propinquarum occisi tradendus est, ut salva tantum anima quidquid de eo facere voluerint habeant potestatem. Seguidamente, en las dos ediciones (recesvindiana y ervigiana de la Lex Visigothorum) se establece lo siguiente: Omnem vero substantiam suam heredibus occisi iuxta legis superioris ordinem iubemus addici, aut etiam fisco, si heredes proximos occisus non reliquerit, sociari. Nam homicida nec facultatibus suis liberatus utetur, etiam si penam mortis evadere mereatur.

76 El mismo tipo de sanciones se establecen en FJ 6,3,7, que lleva la rúbrica: De los que matan sus fiios en el vientre ó despues que son nados. 
de tres disposiciones antiquae. Concretamente en la LV 4,4,1, anti$q u a^{77}$, se establece que si alguien se hace cargo de un niño o una niña abandonados y lo alimenta, posteriormente, si los padres quieren recuperarlo, si se trata de personas libres, han de entregar al alimentador a cambio, o bien un siervo o el pago del precio correspondiente ${ }^{78}$.

En términos similares, se manifiesta el FJ 4,4,1, bajo la rúbrica: Que el omne libre ó la mujer que echa el ninno debe seer siervo ó sierva por él.

Por otra parte, la disposición contenida en la LV 4,4,2, antiqua ${ }^{79}$, se refiere a la exposición del hijo de una sierva; si tiene lugar con conocimiento del amo, se excluye toda reclamación ${ }^{80}$ y quien lo crió es ahora dueño del siervo; si el dueño no tenía conocimiento, se puede recuperar el siervo pagando la tercera parte del precio del mismo al que lo alimentó. La última disposición del título, en LV 4,4,3 ${ }^{81}$, antiqua, no trata propiamente de exposición, sino de contrato de educación de un niño. De tal manera que el niño alimentado hasta cumplir los 10 años devenga un solidus por año y el nutritor dispone de un derecho de retención para cobrar el citado precio. Después de los 10 años, se consi-

$77 \mathrm{LV}$ 4,4,1, antiqua Ut pro exposito infantulo ingenuo serviat qui proiecit.- Si quis puerum aut puellam ubicumque expositum misericordie contemplatione collegerit, et nutritus infans a parentibus postmodum fuerit agnitus, si ingenuorum filius esse dinoscitur, aut servum vicarium reddant, aut pretium. Quod si facere forte neclexerint, a iudice territorii de proprietate parentum expositus redimatur, et parentes huius impietatis auctores exilio perpetuo religentur. Si vero non habuerint, unde filium redimere possint, pro infantulo deserviat qui proiecit, et in libertate maneat propria, quem sevabit pietas aliena. Hoc vero facinus, cum fuerit ubicumque conmmissum, iudicibus et accusae liceat et damnare.

${ }_{78}$ Establece D’ORs: «El Código de Eurico», 151, que la LV 4,4,1, en su forma actual, refleja la mano de Leovigildo.

${ }^{79} \mathrm{LV} 4,4,2$, antiqua. Si servus vel ancilla consciis vel nesciis dominis proicere videantur infantem.- Si ancilla vel servus in fraude fortasse dominorum infantem exposuerint et ipsis insciis infantem proiecerint infans cum fuerit nutritus, tertiam partem pretii nutritor accipiat; ita ut iuret aut probet dominus, se quod servi sui infantem exposuerint ignorasse. Si vero consciis dominis infans probatur fuisse iactatus, in eius, qui nuribit, potestate permaneat. En parecidos términos la disposicion contenida en FJ 4,4,2. Si el siervo ó la sierva echa el ninno sabiéndolo el sennor ó non.

${ }^{80} \mathrm{Cf}$. CTh 5,9,1 y 2 en las notas 34 y 35.

$81 \mathrm{LV}$ 4,4,3, antiqua. Qui a partentibus infantulum acceperit nuriendum, quantum mercedis pro nutritione accipiat premium.- Si quis a parentibus acceperit infantulum nutriendum, usque ad decem annos per singulos annos singulos solidos pretii pro nutrito infante percipiat. Si vero decimum annum etatis excesserit, nihil postea mercedis addatur; quia ipse, qui nutritus est, mercedem suam suo potest conpensare servitio. Quod si hanc summam qui repetit dare noluerit, mancipium in nutrientis potestate permaneat. El contrato de educación de un niño, al que se refiere la citada ley, según D’Ors, «El Código de Eurico», 152, «constituiría una locatio conductio operis, de no haber desaparecido en el Derecho romano vulgar la configuración de las locaciones». 
dera que quedan compensados los gastos de alimentación con los servicios que puede prestar el alimentado ${ }^{82}$.

Otras disposiciones de la ley de los visigodos tienen relación con la venta o donación de los hijos. Así, en la disposición contenida en LV 5,4,12 ${ }^{83}$, antiqua se alude a la prohibición de la venta, donación o pignoración de los hijos. La disposición citada se encuentra en el libro 5 que lleva la rúbrica: De transactionibus, concretamente en el título 4: De conmutationibus et venditionibus. El contrato de compraventa de hijo era nulo: el comprador no adquiría derecho sobre él y perdía el precio entregado. En el Fuero Juzgo, la disposición de la LV citada se encuentra recogida en FJ 5,4,13, bajo la rúbrica: Que los padres non puedan vender los fiios, ni meter en poder de otro, establece lo siguiente: Los padres non puedan vender los fiios, ni dar, ni empennar; ni aquel que los recibiere non debe aver nengun poder sobrellos. Mas el que comprar los fiios del padre pierda el precio; é si fueren empennados, pierda lo que dio sobrellos.

\section{Recepción del Derecho romano en algunos textos legales}

\subsection{Consideraciones generales acerca del ius commune en Europa ${ }^{84}$}

En la historia del Derecho, como es sabido, es cada vez más frecuente la configuración de un período con caracteres peculiares comprendido entre los siglos XIII al XVIII, cuya coherencia consiste en la vigencia del Derecho común, esto es, de un derecho elaborado en las ciudades europeas a partir del siglo XII sobre la base del Derecho romano justinianeo ${ }^{85}$. La penetración del Derecho común en los distintos

${ }^{82}$ FJ 4,4,3, lleva la siguiente rúbrica: Aquel que cria el ninno, quanto debe aver por soldada.

${ }^{83}$ LV 5,4,12, antiqua.- Non licere parentibus filios suos quocumque contractu alterias dominio subiugare.- Parentibus filios suos vendere non liceat aut donare vel obpignorare. Nec ex illis aliquid iuri suo defendat ille, qui acceperit; sed magis pretium vel sepositionis commodum, quod dederat, perdat qui a parentibus filium conparavit.

${ }^{84}$ Una síntesis en relación con el ius commune en Europa puede verse en nuestro trabajo: «La responsabilidad de los daños causados por animales en las personas: en los textos romanos y en códigos medievales españoles», en Estudios de Deusto, vol. 47/2. Julio-Diciembre, 1999, 141 ss.

85 Sobre el particular, GARCía y GARCíA, A.: «El Derecho común en Castilla durante el siglo XIII». Glossae. Revista de Historia del Derecho Europeo, 5-6 (Universidad de Murcia, 1993), 46; al referirse el autor al contenido y formación del Derecho común comienza diciendo que no es fácil describirlo, pero es todavía más difícil definirlo. Y continúa diciendo el citado autor que este enunciado (alude al Derecho común), se refiere al ordena- 
territorios (dentro y fuera de la Península Ibérica) no fue pacífica, sino que tuvo que vencer resistencias más o menos acusadas, de forma que la recepción del Derecho romano-canónico significó en todos los casos la lucha entre un derecho nuevo y el derecho viejo o tradicional de cada país ${ }^{86}$. Como se acaba de hacer mención, en el ius commune se integra también el Derecho canónico, de manera que, según Calasso ${ }^{87}$, puede decirse que el ius commune es la unión indisoluble y típica de las dos leyes universales: canónica y civil, constituyendo así unum ius, ya que la coexistencia en un mismo ordenamiento de dos derechos comunes es conceptualmente inadmisible ${ }^{88}$.

Concretamente, en España, el Derecho romano ha tenido en su desarrollo histórico una importancia fundamental por haber constituido uno de los elementos básicos del Derecho peninsular en sus diversas

miento que emerge de los textos de las colecciones legales justinianeas redescubiertas en el siglo XII, después de seis siglos de eclipse más o menos total o parcial, a los que pronto se sumaron los principales textos canónicos del primer milenio del cristianismo compilados por Graciano hacia 1141-50 y vigorosamente incrementados por las decretales o cartas pontificias y por los concilios generales de la Iglesia desde 1123 hasta 1311-12. Idem, «La penetración del Derecho clásico medieval en España», en AHDE (1966), 575 ss. FonT Rius: «La recepción del Derecho romano en la Península Ibérica durante la Edad Media», en Recueil de memoir et travaux, n. ${ }^{\circ} 6$ (1967), 86 ss. Cf., asimismo, entre otros, PéreZ MARTín, A.: «La obra legislativa alfonsina y puesto que en ella ocupan las Siete Partidas», Glossae. Revista de Historia del Derecho Europeo, 3 (1992), 10 ss. Tomás y VaLIENTE, F.: Manual de Historia del Derecho español (Madrid, 1981), 167.

${ }^{86}$ Entre otros, puede verse, FonT Rius: «La recepción del Derecho romano en la Península Ibérica durante la Edad Media», 92 ss, donde se refiere a las resistencias a la penetración del Derecho romano en el ámbito de la Península Ibérica. Asimismo, TomÁs Y VALiENTE, F.: Manual de Historia del Derecho español, 201. El citado autor dice también a continuación que la mayor o menor intensidad y rapidez de la penetración del Derecho nuevo, del Derecho de los juristas, estaba condicionada por el distinto grado de arraigo, homogeneidad y calidad de los diferentes derechos tradicionales, ibidem, 201.

87 Calasso, F.: Introduzione al Diritto Comune (Milano, 1970), 108.

88 Dos razones señalan los autores, entre ellos CoIng, H.: Derecho privado europeo (Madrid, 1996), 31, por las cuales el Derecho romano-canónico se convirtió en Derecho común: 1) La posición de poder de la Iglesia latina en la Edad Media, y 2) El acontecimiento cultural que es designado usualmente con la expresión de «Recepción». La recepción, como es sabido, tiene su origen en el redescubrimiento científico del Derecho romano, concretamente del Derecho justinianeo, por los juristas italianos, en particular en los siglos XI y XII en Bolonia y cuya compilación legislativa se conoce, como es sabido, a partir de la Edad Media con la expresión Corpus Iuris Civilis. Los glosadores encuentran en el Derecho justinianeo un sistema jurídico completo y desde finales del siglo XI y en el siglo XII se convierte en Bolonia el citado Derecho en la base de la enseñanza jurídica. Además, los glosadores encuentran en el Derecho justinianeo un sistema jurídico completo, estructurado científicamente hasta un cierto grado, que satisfacía al deseo del tiempo por un fundamento racional, entre otros, CoING, H.: Derecho privado europeo, 34 . 
manifestaciones ${ }^{89}$. En la época bajomedieval, con Alfonso X el Sabio, se produce, al igual que en Europa, la recepción del Derecho romano a través del Derecho común. En líneas generales, se pueden distinguir dos épocas en cuanto al romanismo en algunos territorios hispánicos ${ }^{90}$ : en primer lugar, la época del Derecho romano indígena, época anterior a la recepción del Derecho romano común y que corre desde el siglo VI hasta el siglo XII (fines); en segundo lugar, la época de la recepción y del desarrollo del Derecho común, que abarca los siglos siguientes, hasta fines del siglo XVIII, en el cual el ciclo de la penetración e influencia del Derecho romano puede considerarse terminado. Como textos jurídicos pertenecientes a esta segunda época hay que mencionar, entre otros, el Fuero Real y las Siete Partidas, cuyas disposiciones relativas a los límites al ejercicio de la patria potestad vamos a destacar a continuación.

\subsection{El Fuero Real ${ }^{91}$}

Alfonso X elaboró y concedió una importante y sistemática obra que aunque recibió muy diversas denominaciones es, en general, conocida como Fuero Real. Está muy influido por el Liber, ya que fue utilizado por los redactores del citado Fuero como modelo para muchos de sus preceptos. También hay claras influencias de las Decretales del papa Gregorio IX ${ }^{92}$.

En el texto legal mencionado, redactado en 1255, se establece en el prólogo que fue dado con consejo de los sabidores del Derecho, para remediar la falta de fueros, ya que en la mayor parte de sus reinos se juzgaba por fazañas e por albedríos departidos de los omes. Consta el citado texto de cuatro libros que tratan de materia política, religiosa,

89 Véase Larraona y Tabera, A.: «El Derecho justinianeo en España», en Atti del Congresso Internazionale di Diritto Romano, Bologna, II (Pavía, 1935), 85.

${ }^{90}$ Ibidem, 87 ss.

91 A Alfonso X el Sabio se le atribuyen, con mayor o menor grado de certidumbre, tres obras fundamentales: el Fuero Real, el Espéculo y las Partidas y en los tres textos legales se advierte una notoria influencia del Derecho romano canónico. Por lo que respecta al Espéculo, se trata de una obra incompleta, consta de cinco libros y se redactó probablemente entre 1255 y 1260 y recibe este nombre porque en su prólogo se dice de ella que es «espejo» del Derecho.

92 Cf. Tomás y Valiente, F.: Manual de Historia del Derecho español, 164. En relación con el Fuero Real, puede verse, asimismo, entre otros, PÉrez Martín, A.: «El Fuero Real y Murcia», en AHDE, 54 (1984), 55-96. Del mismo autor, «La obra legislativa alfonsina y puesto que en ella ocupan las Siete Partidas», 19 ss. En relación con los Códigos Antiguos de España se ha utilizado la edición de Martínez Alcubilla (Madrid, 1885). 
procedimiento civil y penal. Por lo que respecta al tema de nuestro estudio, el texto alfonsino al que nos estamos refiriendo no concibió el poder paterno como ilimitado y despótico y, así, en FR 3,10,8, bajo la rúbrica: Que cosas no se pueden vender, establece lo siguiente: «...é maguer que el padre haya gran poder sobre los fijos, no queremos que los pueda vender, ni empeñar, ni dar; e quien contra esto los comprare, ó los rescibiere en peños, pierda el precio, é los fijos no hayan ningun daño; é si fuere dado, el donadío no vala».

\subsection{Las Siete Partidas ${ }^{93}$}

La recepción de la patria potestad justinianea, establece Otero ${ }^{94}$, supone volver a poner en práctica aquel poder que se había difuminado por completo en su evolución dentro del ámbito peninsular. En realidad, la patria potestad no fue concebida en las Partidas como un derecho ilimitado del padre. Se la definió como poder y señorío ${ }^{95}$, pero la regulación de las concretas facultades atribuidas al padre denota que aquel poder era limitado.

Las Partidas ${ }^{96}$ recogen plenamente la patria potestas justinianea y además los redactores del texto legal citado dedican una ley ${ }^{97}$ a expli-

93 Bajo este nombre se conoce la obra legislativa más importante de toda la historia jurídica española, $c f$. PÉREZ MARTín, A.: «La obra legislativa alfonsina y puesto que en ella ocupan las Siete Partidas», 30 ss. Constituyen un cuerpo jurídico de mayor alcance que el texto legal del Fuero Real por su planteamiento más doctrinal y su entidad más bien enciclopédica y puede considerarse el libro jurídico más representativo de la recepción del Derecho común en Castilla, $c f$. Clavero, B.: Temas de Historia del Derecho: Derecho de los Reinos (Sevilla, 1990), 98. Por lo que respecta al Derecho romano, podemos destacar la influencia del mismo, sobre todo en el campo del Derecho privado y del penal en los textos medievales a que aludimos, García y García, A.: «El Derecho común en Castilla durante el siglo XIII», Glossae. Revista de Historia del Derecho Europeo, 5-6 (Murcia, 1993-94), 55. La influencia de las leyes romanas fue puesta ya de relieve por MARTínEZ MARINA: Ensayo crítico sobre la antigua legislación y principales cuerpos legales de León y de Castilla, especialmente sobre el Código de las Siete Partidas (Madrid, 1808), reeditado por Martínez Cerdos, J.: Obras escogidas de Martínez Marina (Madrid, 1966), 372 ss.

94 Otero, A.: «La patria potestad en el Derecho histórico español», 232. En el Derecho aragonés no se realizó una recepción de la patria potestad justinianea, por lo cual llega hasta el Apéndice en la forma en que había quedado en su evolución medieval. Vid. GARCÍA-AtAnCE, M.: «De consuetudine Regni non habemus patriam potestatem», en Anuario de Derecho Aragonés, 6 (1951-1952), 157-172.

95 Part. 4,17: Del poder que han lo padres sobre sus fijos, de qual natura quier que sea. Después de la citada rúbrica, establece, entre otras cosas, que "poder e señorio, han los padres sobre los fijos segund razon natural, e segund derecho».

96 Cf. Partidas 4,17 y 18.

97 Partida 4,17,3. Además, las Partidas concibieron la patria potestad como instituto natural al proclamar en Partida 4,17, proemio, lo siguiente: Poder, e señorio, han los pa- 
car el alcance dado al término potestas, «... se toma esta palabra potestas del padre como ligamiento de reuerencia, e de subieción, e de castigamiento que deue auer el padre sobre su fijo». Asimismo, se refiere la ley a «la piedad, e debdo natural que deben mouer a los padres, para criar a los hijos, dandoles, e faziendoles lo que es menester, segund su poder... ${ }^{98}$. Así pues, el texto alfonsino de las Partidas advierte que el castigo paterno debe ser con mesura, estableciéndose en la Part. 4,18,1899 una serie de razones por las que el padre puede perder la patria potestas sobre sus hijos.

Por lo que respecta a las amplias facultades que el Derecho romano reconoció al paterfamilias, en primer lugar hay que decir que las Partidas no reconocen un ius vitae necisque al padre. Solamente puede ejercer este derecho en un caso excepcional, como es: el de que el padre, cercado en un castillo que tenga de señor, se vea acosado por el hambre y no tenga qué comer, al que se refiere en Partidas $4,17,8^{100}$ y ello como una manifestación del poder que ha el padre sobre sus fijos que son en su poder, según la ley. Por lo demás, el padre tiene asignado un derecho de correción, correlativo al deber de educación de los hijos. Precisamente el texto alfonsino se refiere a la pietas que debe informar las relaciones de los padres con los hijos; en caso contrario, puede incurrir en alguna causa que supone la pérdida de la patria potestad ${ }^{101}$.

En cuanto al ius vendendi del pater, las Partidas reflejan el Derecho justinianeo, aunque con alguna limitación. Recordemos que en la legis-

dres sobre los fijos segund razon natural, e segund derecho. Lo uno, porque nascen dellos; lo al, porque han de heredar lo suyo. La misma concepción resplandeció en los juristas españoles del siglo XIX. Podemos referirnos concretamente a GómEZ DE LA SERNA Y MONTalbán, J.M.: Elementos del Derecho Civil y Penal de España, 11. a ed. (Madrid, 1874), 498 , donde establecen que la patria potestad «está fundada en la naturaleza, que ha establecido el amor de los padres y el reconocimiento de los hijos». Asimismo, la doctrina española moderna ve también en la patria potestad una facultad natural, $c f$. PUIG PEÑA, F.: Tratado de Derecho civil español, t. II, vol. II (Madrid, 1946), 147.

98 Cf. Part. 4,19, proemio. «... Ca si las bestias, que non han razonable entendimiento, aman naturalmente, e crian sus fijos, mucho mas lo deuen fazer los omes, que han entendimiento, e sentido sobre todas las otras cosas».

99 Part. 4,18,18: Porque razones pueden los padres ser constreñidos, que saquen de su poder sus fijos.- Fallamos quatro razones, porque pueden constreñir al padre, que saque de su poder a su fijo: como quier que diximos en las leyes ante desta, que lo non podrian apremiar que lo fiziesse. La primera es, quandol padre castiga el fijo muy cruelmente, $e$ sin aquella piedad quel deue auer, segund natura...

${ }_{100}$ Partidas 4,17,8, que lleva la siguiente rúbrica: Porque razones puede el padre vender o empeñar su fijo.

101 Partidas 4,18,18. Porque razones pueden los padres ser constreñidos, que saquen de su poder sus fijos. 
lación de Justiniano, como se ha visto supra, el ius vendendi quedaba limitado a los casos de extrema pobreza y se admitió que el hijo vendido pudiese volver a recobrar la libertad si se devolvía el precio entregado por él u otro esclavo, a cambio. En la Partida 4,17,8 ${ }^{102}$ se permite al padre vender o empeñar a su hijo sólo en caso de que sufra tal hambre o situación de gran pobreza que no pueda de otro modo remediar la grave situación; y el mismo legislador se apresura a justificar esta excepción, advirtiendo que con ella se trata de evitar que mueran tanto el padre como el hijo. Asimismo, se establece en la disposición siguiente ${ }^{103}$ que si se ha vendido el hijo como consecuencia de la grave situación mencionada, deue ser tornado en libredumbre, si el mismo hijo u otro por él dan el precio por el que fue vendido. Establece además la citada disposición que, si el comprador le hubiese enseñado algún oficio o arte, se le debe dar, además, aquello que los peritos estimaren por encima del precio pagado como consecuencia de los conocimientos recibidos.

Como consecuencia de las limitaciones a las que se ha hecho referencia, se ha de destacar que la regulación de las causas de pérdida del poder paterno - $\mathrm{y}$ singularmente el hecho de sancionar con dicha pérdida al padre que castigue cruelmente al hijo o prostituya a la hi$\mathrm{ja}^{104}$ - denota suficientemente una concepción de la patria potestad como poder limitado.

Finalmente, hay que señalar que, además de los poderes que se le conceden al padre sobre sus hijos, le conceden asimismo las leyes del texto alfonsino acciones para ejercerlos. Así, el padre puede reclamar al hijo retenido por la fuerza y que está en poder de otro y también

102 Partidas 4,17,8. Porque razones puede el padre vender o empeñar su fijo.- Qvexado seyendo el padre de grand fambre, e auiendo tan grand pobreza, que non se pudiesse acorrer dotra cosa, estonce puede vender, o empeñar sus fijos, porque aya de que comprar que coma. E la razon porque puede esto fazer, es esta porque pues el padre non han otro consejo: porque pueda estorcer de muerte el, nin el fijo: guisada cosa es, quel pueda vender, e acorrerse del precio: porque non muera el uno, ni el otro...

103 Partidas 4,17,9.- Como se puede redemir el fijo que vendiere su padre, é tornar en su libertad.- Por cuyta de fambre vendiendo el padre a su fijo, segund dize en la ley ante desta, dando el mismo por si quel precio porque fue vendido, u otro or el: deue ser tornado en libredumbre. Pero si aquel despues quel compro, le mostro algund menester, o alguna sciencia, porque valiesse mas que a la sazon quel compro: non es tenudo de darle por el precio que el dio tan solamente, antel deue darle mas del precio, quanto fallaren en verdad conmunalmente omes buenos e sabidores, que vale mas por razon de aquello, que despues aprendio, o quanto despendio de lo suyo, en fazerle aprender.

104 Cf. Partida, 4,18,18, Porque razones pueden los padres ser constreñidos, que saquen de su poder sus fijos, citada asimismo en la nota 101. 
puede reclamar judicialmente al hijo que abandone la casa paterna para que vuelva a la misma ${ }^{105}$.

\section{Ley de Matrimonio Civil de $\mathbf{1 8 7 0}^{106}$}

El régimen de la patria potestad justinianea rige hasta la Ley de Matrimonio Civil de 1870, con algunas modificaciones como las que establecieron concretamente las Leyes $47^{107}$ y $48^{108}$ de Toro. La citada Ley introduce algunas modificaciones importantes, como son las incluidas en el artículo $64^{109}$, de manera que la patria potestad se convertía así en un poder temporal. Poder paterno, limitado, como establece el artículo 65 de la propia Ley, ya que reconoce a los padres el derecho de corregir y castigar moderadamente a los hijos. Por lo que se refiere al ámbito de las relaciones personales, los padres tienen derecho a que sus hijos legítimos no emancipados vivan en su compañía. Se les atribuye asimismo a los padres un derecho de correción sobre sus hijos ${ }^{110}$.

En la realidad social, establece Castán ${ }^{111}$, «ya desde mucho antes venía acentuándose la convicción de que la patria potestad es función establecida en beneficio de los hijos; la literatura ofrece numerosas muestras de repulsa contra el uso arbitrario del poder paterno» ${ }^{112}$. Tam-

$105 C f$. Partidas 417,10. Que el padre puede demandar al juez quel torne su fijo a su poderío, si non lo touier, o el fijo nol le quisiere obedecer.

106 Los efectos que se atribuyen a la patria potestad en la Ley de Matrimonio Civil de 1870 no difieren fundamentalmente de los de la patria potestas justinianea en lo que se refiere al contenido patrimonial, vid. OTERO: «La patria potestad en el Derecho histórico español», 240.

107 Ley 47. El juez con conocimiento de causa legitima ò necesaria compela al marido que de licencia á su mujer para todo aquello que ella no podría hacer sin licencia de su marido, e si compelido no se la diere, que el Juez, solo se la pueda dar.

${ }^{108}$ Ley 48 de Toro: El marido pueda ratificar lo que su muger oviere hecho sin su licencia no embargante que la dicha licencia no haya precedido: ora la ratificacion sea general, ó especial.

109 Artículo 64: «El padre, y en su defecto la madre, tienen potestad sobre sus hijos legítimos no emancipados. Se reputará emancipado de derecho al hijo legítimo desde que hubiere entrado en la mayor edad». Este precepto será recogido por el artículo 154 de nuestro Código Civil, en su redacción originaria.

110 Art. 65 de la Ley de Matrimonio Civil: En consecuencia de tal potestad, el padre y, en su defecto, la madre tendrán derecho: $1 .^{\circ}$ A que sus hijos legítimos no emancipados vivan en su compañía, y a representarlos en juicio en todos los actos jurídicos que le sean favorables. $2 .^{\circ}$ A corregirlos y castigarlos moderadamente.

111 CASTÁn VázQUez, La patria potestad, 30.

112 Cf. Ossorio MoRales: Derecho y Literatura (Universidad de Granada, 1949), $42-44$. 
bién en la doctrina jurídica se iba imponiendo la concepción moderna. Determinados autores veían la patria potestad en el siglo XVIII, como un poder útil al hijo e insistían en la necesidad de «considerar este poder muy distante de aquel derecho de vida y muerte que permitieron las leyes romanas sobre los hijos» ${ }^{113}$.

\section{Concepción moderna de la autoridad paterna}

En los Derechos del mundo occidental está muy extendida la concepción de la patria potestad como una función atribuida al padre para protección de los hijos ${ }^{114}$. Asimismo, algunos autores consideran que «la patria potestad es un poder fundamentalmente tuitivo, destinado a la protección de los menores desde el momento de su nacimiento hasta que alcancen la plena capacidad de obrar» ${ }^{115}$.

En el presente apartado, en la misma línea de lo que hemos visto en etapas históricas anteriores, nos interesa destacar, fundamentalmente, las limitaciones legales al ejercicio de la patria potestad atribuida a los padres.

El Código Civil español, en la redacción originaria del número $2 .^{\circ}$ del artículo 155, atribuyó expresamente a los padres, respecto de los hijos, «la facultad de corregirlos y castigarlos moderadamente». Por otra parte, en los artículos 156 a 158 reguló también el citado texto legal, un derecho de los padres a corregir a los hijos, no ya directamente, sino a través del Estado, reclamando la intervención del Juez municipal para imponer a los hijos hasta un mes de detención en establecimiento correccional destinado al efecto. De manera que el ius puniendi del pater familias consistía en un poder de imponer sanciones o penas como consecuencia de los actos anormales o irregulares del hijo sin necesidad de fundar la decisión y sin posible recurso contra ella. A partir de la reforma del Código como consecuencia de la Ley de 13 de mayo de 1981, ha desaparecido el citado ius puniendi y se limita a mencionar el derecho al castigo en el último apartado del nuevo artículo 154, donde se establece lo siguiente: «Los padres podrán, en el ejercicio de su potestad, recabar el auxilio de la autoridad. Podrán también corregir razonable y moderadamente a los hijos». Consideran algunos autores «que

113 De Asso y del Río, Jordán y De Manuel y Rodríguez, Miguel: Instituciones del Derecho civil de Castilla, ed. sexta, corregida notablemente (Madrid, 1805), 67.

114 CASTÁn VÁzQUEZ: La patria potestad, 31

115 DíEZ-Picazo y Gullón, A.: Sistema de Derecho civil, vol. IV. Derecho de familia y Derecho de sucesiones, vol. IV, 2. ${ }^{\mathrm{a}}$ ed. (Madrid, 1982), 366. 
la diferencia sustancial entre la facultad de corrección y la del castigo es que no tiene por objeto sancionar actos ilícitos o irregulares, sino que es una consecuencia del deber de educación y de instrucción y tiene que llevarse a cabo en función pedagógica, porque corregir hay que entenderlo como sinónimo de rectificar. Significa ello que los actos de ejercicio de la patria potestad que no tengan esa finalidad, ese sentido o esa motivación deben ser considerados como extralimitaciones y provocar las consecuencias que de ello haya que extraer» ${ }^{116}$.

Si como acabamos de ver, el artículo 154 concede a los padres la facultad de castigar a los hijos de forma «razonable»y «moderadamente», lo que no se puede admitir, por tanto, es el abuso en el derecho de correción ${ }^{117}$; en este sentido, pueden considerarse, por ejemplo, como castigos excesivos, «los golpes y encierros que pongan en peligro la salud o la vida del menor, o la privación a éste de cosas necesarias» ${ }^{118}$.

En la legislación española, el castigo excesivo puede producir consecuencias de orden civil (privación de la patria potestad) y de orden penal. En primer lugar, en el ámbito civil, el artículo 171 del C.c., en su redacción originaria, establecía que «los Tribunales podrán privar a los padres de la patria potestad, o suspender el ejercicio de ésta, si trataren a sus hijos con dureza excesiva». Tras la reforma citada anteriormente de 1981 el nuevo artículo $170^{119}$ del Código, se refiere a la privación total o parcial de la patria potestad y no menciona ese trato de dureza excesiva; no obstante, «parece que el mismo seguiría siendo causa de privación como contrario a toda la concepción que en la patria potestad

116 Vid. Díez-Picazo y Gullón, A.: Sistema de Derecho Civil, 367. Además, como establece CASTÁn VÁzQuez: Comentarios al Código Civil y Compilaciones forales, tomo III, vol. 2 (Madrid, 1982), 130. La doctrina civil extranjera y española ha hecho aplicación de la teoría del abuso del derecho al concreto ejercicio de la patria potestad.

117 Según establece Castán VÁzQuez: Comentarios al Código Civil y compilaciones forales, 130: «Hoy se admite generalmente que el derecho de corrección ha de ejercitarse dentro de ciertos límites fuera de los cuales la conducta del padre se convierte en antijurídica». Sobre el abuso del derecho de corrección, entre otros, $c f$. RodRíGuEZ-ARIAS: $E l$ abuso del Derecho, 2. ${ }^{\mathrm{a}}$ ed. (Buenos Aires, 1971), 143. LAQUIS: El abuso del Derecho en el ejercicio de la patria potestad. Asimismo, el estudio acerca del abuso del Derecho que sirve de comentario al nuevo artículo 7.2 del C.c. de RocA, Juan: Comentarios a las reformas del C.c. (Madrid, 1977), vol. I, 371 ss.

118 CASTÁN VÁzQuez: Comentarios al Código Civil y compilaciones forales, 130.

119 Art. 170 del C.c., establece: «El padre o la madre podrán ser privados total o parcialmente de su potestad por sentencia fundada en el incumplimiento de los deberes inherentes a la misma o dictada en causa criminal o matrimonial». 
inspira al Código» ${ }^{120}$. En el orden civil, asimismo, los malos tratos de los padres pueden dar lugar al depósito de $\operatorname{los}_{\text {hijos }}{ }^{121}$ y ser causa de desheredación ${ }^{122}$.

En el orden penal, el castigo excesivo de los padres puede llegar a constituir falta o delito. Así, los padres que golpearen o maltrataren de obra sin causar lesión al hijo, serán autores de la falta del artículo 617.2 del Código Penal. Existe un derecho de corrección de los padres respecto a los hijos menores de edad, que deriva de la patria potestad de aquéllos sobre éstos; no obstante, el maltrato de obra sólo está justificado por el derecho de corrección cuando es compatible con los deberes derivados de la patria potestad, es decir, cuando es ejercitado moderadamente ${ }^{123}$. Si producen heridas de mayor consideración, serán reos de los delitos de lesiones del artículo 147 del mismo cuerpo legal. Hay que tener asimismo en cuenta que si se ejerce habitualmente violencia física o psíquica sobre determinadas personas (están incluidos, entre otros, los hijos propios o del cónyuge o conviviente), el autor de los actos de violencia a los que se refiere el artículo $153^{124}$ del Código será castigado con la pena de prisión de seis meses a tres años, sin perjuicio de las penas que pudieran corresponder a los delitos o faltas en que se hubieran concretado los actos de violencia física o psíquica.

Si los padres, castigando al hijo, llegaran a producirle la muerte, pueden ser sancionados como autores del delito de homicidio previsto y penado en el artículo 138 del Código Penal. Como es sabido, el Código Penal vigente ha suprimido las figuras autónomas de parricidio e infanticidio tipificadas en el Código anterior. No obstante, si bien se pierde el nomen iuris específico de tales figuras, se mantiene la circunstancia mixta de parentesco, recogida en el artículo 23 del Código 1987.

120 CASTÁn VÁzQuez: Comentarios al Código Civil y compilaciones forales, 131.

$121 C f$. las sentencias de 30 de octubre de 1984, 11 de junio de 1986 y 9 de enero de

${ }^{122} C f$. el artículo 854 del C.c.

123 Cf. López Barja y Pérez del Valle: Código Penal. Doctrina y Jursiprudencia, tomo, 2, arts. 138 a 385 (Madrid, 1997), 5023.

${ }^{124}$ El artículo 153 ha sido modificado por LO 14/1999, de 9 de junio, de modificación del Código Penal en materia de protección a las víctimas de malos tratos, y de la Ley de Enjuiciamiento Criminal. El contenido del citado artículo es el siguiente: El que habitualmente ejerza violencia física o psíquica sobre quien sea o haya sido su cónyuge o sobre persona que esté o haya estado ligada a él de forma estable por análoga relación de afectividad, o sobre los hijos propios o del cónyuge o conviviente, pupilos ascendientes o incapaces que con él convivan o que se hallen sujetos a la potestad, tutela, curatela, acogimiento o guarda de hecho de uno u otro, será castigado con la pena de prisión de seis meses a tres años, sin perjuicio de las penas que pudieran corresponder a los delitos o faltas en que se hubieran concretado los actos de violencia física o psíquica. 
actual que podrá agravar o atenuar, según la naturaleza, los motivos y los efectos del delito, la figura básica del homicidio contemplada en el citado artículo $138 .{ }^{125}$

Por lo que respecta a la entrega a terceros del propio hijo, representa la superación de la ya histórica exposición a que aludía el artículo $468.2^{126}$ del derogado Código Penal. Si la entrega está presidida por el ánimo lucrativo, entraría en juego el tipo agravado previsto en el artículo $221^{127}$ del Código Penal vigente ${ }^{128}$.

125 Cf. Ruiz Vadillo, E.: Código Penal. Doctrina y Jurisprudencia, tomo 2, arts. 138 a 385 (Madrid, 1997), 1719 ss.

${ }^{126}$ En el artículo 468, la suposición de partos y la sustitución de un niño por otro, se castigaban con las penas de prisión menor y multa de 100.000 a 1.000 .000 de pesetas. El párrafo $2 .^{\circ}$ establecía: «Las mismas penas se impondrán al que ocultare o expusiera a un hijo con ánimo de hacerle perder su estado civil».

127 Art. 221.1. Los que, mediando compensación económica, entreguen a otra persona un hijo descendiente o cualquier menor aunque no concurra relación de filiación o parentesco, eludiendo los procedimientos legales de la guarda, acogimiento o adopción, con la finalidad de establecer una relación análoga a la de filiación, serán castigados con las penas de prisión de uno a cinco años y de inhabilitación especial para el ejercicio del derecho de patria potestad por tiempo de cuatro a diez años.

128 Vid. Marchena Gómez, M.: Código Penal de 1995. Comentariosy jurisprudencia. Coordinación editorial: I. Serrano Butragueño (Granada, 1999), 1146. 